\title{
Mathematical Modeling of Drying of Black Liquor Droplets in Recovery Boilers
}

\author{
S. Ramesh, H. Mahalingam, and N. J. Rao
}

\begin{abstract}
In this paper, the drying of black liquor droplets sprayed into the chemical recovery boiler in a pulp and paper mill is examined. The fate of the droplets in the recovery boiler is generally divided into three consecutive stages i.e., drying, devolatilization and char combustion. Drying refers to the removal of water from the black liquor droplets by upward moving hot gases during its flight in the recovery boiler. When the black liquor is atomized in the hot ambience of the recovery boiler, different sizes of droplets are generated, some of which are not desirable with regard to incomplete drying. This creates problems in operation of the recovery boiler. A simple mathematical model is developed to estimate the travel time from the point of injection to the char bed. Simulations were carried out for various parameters including droplet size and suitable droplet sizes determined for safe and economical boiler operation.
\end{abstract}

Index Terms-Black liquor, drying, modeling, recovery boiler, droplet size

\section{INTRODUCTION}

Black Liquor is generated during the process of pulp production in a chemical digester and this process is called cooking or pulping [1]. Cooking is the process of extraction of cellulose fibers present in the stock by freeing the cellulose from the lignin content. Cooking of the wood chips is carried out at temperatures of around $165^{\circ} \mathrm{C}$ and pressures of 5-6 $\mathrm{kg} / \mathrm{cm}^{2}(\mathrm{~g})$ in the presence of an inorganic chemical solution (consisting of approximately $60 \mathrm{wt} \%$ Sodium Hydroxide, 25 wt $\%$ Sodium Sulfide and $15 \mathrm{wt} \%$ Sodium Carbonate). After cooking, the cellulose fibers are separated by filtration and the resulting filtrate is called weak black liquor. This weak black liquor contains valuable inorganic and organic chemicals. Recovery of these chemicals in the form of either heat energy or chemicals play a crucial role in the overall economics of the pulp and paper industry. The weak black liquor is then concentrated in multiple-effect evaporators and fed into a chemical recovery boiler for recovering heat and chemicals.

The droplets are generated by spraying black liquor into the recovery furnace. The droplets, which are essentially spherical in shape, move down in the recovery furnace encountering a stream of rising hot gases. The droplet receives heat from the hot gases, loses water by evaporation and the process continues till all the moisture is removed. This is the drying phase. It may be noted that due to the presence of inorganic solids, the

Manuscript received August 10, 2013; revised October 16, 2013.

The authors are with the Department of Chemical Engineering, Jaypee University of Engineering \& Technology, A-B Road, Dt. Guna - 473226, M. P., India (tel: +917544 267310; fax: +91 7544 267011; e-mail: hari.mahalingam@juet.ac.in). boiling point of the black liquor is elevated to the order of around $20^{\circ} \mathrm{C}$ above the normal boiling point of water. The dried particles move further down experiencing simultaneous heat transfer and mass transfer (devolatilization). During this process, the temperature of the particle (droplet) increases and the particle finally hits the char bed at the bottom of the furnace.

In the char bed, combustion takes place and the hot gases move upwards. The fate of the droplet from the point of injection till it hits the char bed essentially has 3 distinct phases as listed below.

1) Drying

2) Devolatilization

3) Char Combustion

In the present paper, an attempt is made to develop a mathematical model for the drying phase of the black liquor droplets involving downward movement with simultaneous heat and mass transfer. The aim is to map out the desirable droplet sizes for optimal recovery boiler operations such that the drying is complete and devolatilization takes place to the desired extent. Modeling of combustion in black liquor droplets has been studied by many researchers and an excellent review of the various models proposed is available in [2]. Jarvinen [3] presents a detailed mathematical model for the black liquor devolatilization and swelling which however involve the complex numerical solution of coupled partial differential equations for the mass and heat balances concerning the droplet. It is the intention of this paper to present a simple mathematical model for the drying and devolalization phases of the black liquor droplet trajectory that can be solved using the method of finite differences. In the first part, it is sought to model the drying phase of the droplet.

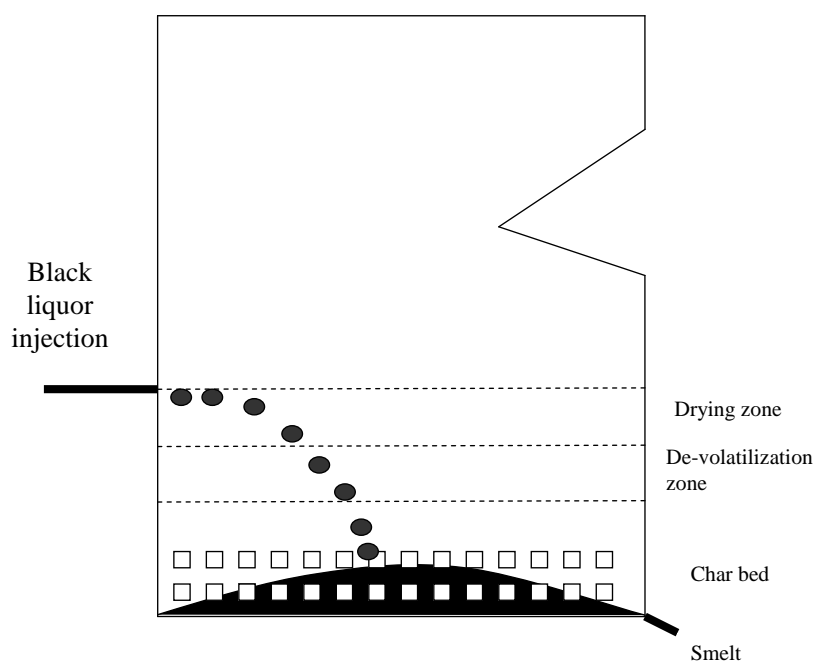

Fig. 1. Sketch of a black liquor recovery boiler. 
Recovery boilers (please see Fig. 1 for a typical sketch) are generally designed to have a hearth loading of approximately 2.5 MW/ $/ \mathrm{m}^{2}$ and accordingly, for a 1000 tons per day black liquor solids handling recovery boiler, the furnace cross sectional area is around $64 \mathrm{~m}^{2}[4]$. The furnace gas velocity is one of the critical parameters which decide the range of the particle size distribution. The desired particle size distribution shifts to higher side with increase in gas velocity.

The gas temperature is highest in the combustion area and goes down to about $900^{\circ} \mathrm{C}$ at the point of black liquor injection which is about $5.5 \mathrm{~m}$ from the base of the char bed. The gas velocity varies with temperature and is generally in the range of $3-5 \mathrm{~m} / \mathrm{s}$. A mathematical model is developed to predict simultaneous heat $\&$ mass transfer from the black liquor droplet as outlined in Section II.

\section{Development of Mathematical Model}

The black liquor droplet, which is assumed to be spherical in shape, moves down under the influence of gravitational \& buoyancy forces in an up moving gas stream. Heat transfer occurs from the gas to the particles by a combination of convective and radiative heat transfer resulting in the simultaneous evaporation of water. During the process of combined heat and mass transfer, the diameter of the droplet is assumed to be constant which is a reasonable assumption considering that the black liquor droplets are highly viscous due to the high solids concentration and that pores are created by the water vapor escaping from the droplet. The size of the pores depends on the rate of evaporation. The principal equations to calculate the furnace gas velocity, heat transfer, particle velocity and mass transfer occurring in the black liquor recovery boiler furnace are given below.

\section{A. Furnace Gas Velocity}

The continuity equation for the furnace gas mass flow rate [4] is written as

where

$$
\bar{W}_{f g}=\rho_{g} A_{f} U_{g}
$$

$\bar{W}_{f g}:$ Furnace gas mass flow rate, $\mathrm{kg} / \mathrm{s}$

$A_{f}$ : Furnace cross-sectional area, $\mathrm{m}^{2}$

$\rho_{g}:$ Density of the gas, $\mathrm{kg} / \mathrm{m}^{3}$

$\mathrm{U}_{\mathrm{g}}$ : Furnace gas velocity, $\mathrm{m} / \mathrm{s}$

The furnace gas velocity [2] is determined by

$$
U_{g}=\frac{T_{g K} G_{f}\left(0.55+\frac{1-B L_{\text {conc }}}{B L_{\text {conc }}}+A F S(1+e / 100)\right)}{334 . A_{f}}
$$

$B L_{\text {conc }}$ : Concentration of Black liquor droplet, wt $\%$

$G_{f}$ : Capacity of the boiler, $\mathrm{kg} / \mathrm{s}$ of Black Liquor Solids

$e$ : Excess air in $\%$

\section{AFS: Air-Fuel Stoichiometric Ratio}

$T_{g K}$ : Temperature of gas, $K$

Equation (2) helps in calculating the upward gas velocity as a function of the prevailing gas temperature in the furnace. For this purpose, the temperature of the gas is assumed to vary with the travel distance of the droplet from the injection point to the char bed in four distinct slabs as follows: between distances of $0-1 \mathrm{~m}$, it is $900^{\circ} \mathrm{C}$; in the next $1-2 \mathrm{~m}$, it is $1000^{\circ} \mathrm{C}$; between
2- $3 \mathrm{~m}$, it is $1100^{\circ} \mathrm{C}$ and beyond $3 \mathrm{~m}$, it is $1200^{\circ} \mathrm{C}$. The values of $e$ and AFS used in this paper are $15 \%$ and 4.56 respectively [4].

\section{B. Particle Velocity}

The droplet movement is affected by gravitational $\left(F_{G}\right)$, buoyancy $\left(F_{B}\right)$ and drag $\left(F_{D}\right)$ forces. The net sum of these forces causes change in momentum and decides the velocity of the particle at any point of travel [3]

$$
\Sigma \vec{F}=\frac{d\left(m_{p} u_{p}\right)}{d t}
$$

The gravitational force $\left(\mathrm{F}_{\mathrm{G}}\right)$, which acts vertically downward on the particle, depends on the density of the particle.

$$
\vec{F}_{G}=\frac{\pi \rho_{p} D_{p}^{3} g}{6}
$$

Buoyancy Force $\left(F_{B}\right)$ which acts vertically upward on the particle and it depends on the density of the gas.

$$
\vec{F}_{B}=\frac{1}{6} \pi \rho_{g} D_{p}^{3} g
$$

The drag force $\left(\vec{F}_{D}\right)$ is exerted by the fluid on the particle and it decides the fate of the particle i.e., whether it is carried away by the up-moving gas or moves down. The magnitude of the drag force depends on the relative (slip) velocity $\left(u_{s}\right)$ of the particle. Normally, the particle and gas move in the opposite directions with the direction of the gas being upward and these respective directions are represented as positive. Hence, the relative velocity is equal to the sum of gas and particle velocities as indicated in (6).

$$
\begin{gathered}
\vec{u}_{s}=\vec{u}_{g}+\vec{u}_{p} \\
\vec{F}_{D}=\frac{1}{8} \pi C_{D} \rho_{g} D_{p}^{2} \vec{u}_{s}^{2}
\end{gathered}
$$

For particle Reynolds number, $R e_{p}<3 \times 10^{5}$ and spherical particles, $C_{D}$ [5] can be obtained from the following correlation (8).

$$
C_{D}=\frac{24}{R e_{p}}\left(1+0.15 R e_{p}^{0.687}\right)+\frac{0.42}{1+4.25 \times 10^{4}\left(\operatorname{Re}_{p}^{-1.16}\right)}
$$

In the hot ambience of the recovery boiler, favorable droplet dynamics for maximizing chemical \& energy recovery and operation cycle of the recovery boiler dictate the downward movement of the droplet against the rising hot gases.

Hence (3) can be modified as given below.

$$
F_{G}-F_{B}-F_{D}=\frac{d\left(m_{p} u_{p}\right)}{d t}
$$

Substitution of (4), (5) \& (7) into (9) yields

$$
\frac{d u_{p}}{d t}=\frac{\left(\rho_{p}-\rho_{g}\right)}{\rho_{p}} g-\frac{3 C_{D} \rho_{g}}{4 D_{p} \rho_{p}}\left(u_{g}+u_{p}\right)^{2}
$$

When the particle reaches its terminal velocity, the drag force is exactly equal and opposite to the net force of gravity at which point,

$$
\frac{d u_{p}}{d t}=0
$$


and

$$
u_{t}=\left(\frac{4 D_{p}\left(\rho_{p}-\rho_{g}\right) g}{3 C_{D} \rho_{g}}\right)^{0.5}
$$

Equation (10) has been discretized to calculate the particle velocity in the recovery boiler as shown below.

$$
u_{p}^{j+1}=u_{p}^{j}+\left[\frac{\left(\rho_{p}-\rho_{g}\right)}{\rho_{p}} g-\frac{3 C_{D} \rho_{g}}{4 D_{p} \rho_{p}}\left(u_{g}+u_{p}^{j}\right)^{2}\right] \times \Delta t
$$

\section{Heat transfer to the particle}

When the black liquor droplet moves down in the hot ambience of furnace, heat is transferred to particle in the form of convective heat transfer from the surrounding hot gases and radiation heat transfer from the char bed. In this section, equations are given for finding out the quantum of heat that is transferred to the particle both by convective and radiation heat transfer.

\section{1) Heat transfer by convection}

The heat $\left(Q_{\text {conv }}\right)$ that is to be transferred to a spherical drop by convection [4] is

$$
Q_{\text {conv }}=h A \Delta T
$$

where

$h$ : Convective Heat Transfer coefficient $\left(\mathrm{W} / \mathrm{m}^{2} . \mathrm{K}\right)$

$A$ : Surface area of the particle $\left(\mathrm{m}^{2}\right)$

$\Delta T$ : Temperature difference between that of the gas $\left(T_{g k}\right)$ and droplet $\left(T_{p K}\right)$

The temperature of the droplet is calculated by the expression given below.

$$
T_{p K}=T_{B P}^{W}+T_{B P}^{E}+273.15
$$

where

$T_{B P}^{W}$ : Normal Boiling point of water, $100^{\circ} \mathrm{C}$

$T_{B P}^{E}$ : Boiling Point Elevation, ${ }^{\circ} \mathrm{C}$

Boiling point elevation $\left(T_{B P}^{E}\right)$ of the black liquor [4] due to presence of salts and alkali is given by

$$
T_{B P}^{E}=0.035\left(100 \times B L_{\text {conc }}\right)^{2}-\left(4.292 \times 100 \times B L_{\text {conc }}\right)+145
$$

The convective heat transfer coefficient [6] is calculated from (24), a correlation involving the dimensionless Nusselt number as a function of the dimensionless Grashof number $(\mathrm{Gr})$ and particle Reynolds number $\left(R e_{p}\right)$.

$$
N u=2+0.39 G r^{0.25}+0.37 R e_{p}^{0.6}
$$

The thermal conductivity $(k)$ data of air is taken from [7] and this data is fitted to a linear equation (25) which is used in the range of 1173 to $1473 \mathrm{~K}$.

$$
k=7 \times 10^{-5} T_{g K}+0.004
$$

The viscosity of the gas is calculated by Sutherland parameters given in [8].

\section{2) Heat transfer by radiation}

The equations for calculating the heat transfer due to radiation $\left(Q_{\text {rad }}\right)$ from the char bed are given below [9].

$$
Q_{r a d}=A \sigma\left(\alpha\left(T_{c b K}\right) T_{c b K}^{4}-\varepsilon\left(T_{p K}\right) T_{p K}^{4}\right)
$$

where

$$
A \text { : Surface area of the particle, } \mathrm{m}^{2}
$$

$\sigma:$ Stefan-Boltzmann constant $\left(5.6696 \times 10^{-8} \mathrm{~W} / \mathrm{m}^{2} \cdot \mathrm{K}^{4}\right)$

$\alpha\left(T_{c b K}\right):$ Absorptivity

$\varepsilon\left(\mathrm{T}_{\mathrm{pK}}\right):$ Emissivity

$T_{c b K}$ : Incident Radiation (char bed) Temperature (K)

The absorptivity and emissivity are calculated by the following correlations [7].

$$
\begin{aligned}
& \alpha\left(T_{i}\right)=C_{0}+\left(C_{1}\right)\left(T_{c b K}\right)+\left(C_{2}\right)\left(T_{c b K}^{2}\right)+\left(C_{3}\right)\left(T_{c b K}^{3}\right) \\
& \varepsilon\left(T_{s}\right)=C_{0}+\left(C_{1}\right)\left(T_{p K}\right)+\left(C_{2}\right)\left(T_{p K}^{2}\right)+\left(C_{3}\right)\left(T_{p K}^{3}\right)
\end{aligned}
$$

where $C_{0}=0.97009, C_{1}=4.9316 \times 10^{-5}, C_{2}=-5.3758 \times 10^{-8}$, $C_{3}=1.0892 \times 10^{-11}$

The total heat received by the droplet is $Q_{\text {total }}$ as given in (29).

$$
Q_{\text {total }}=Q_{\text {conv }}+Q_{\text {rad }}
$$

\section{Drying}

Drying of the black liquor is not an exclusive phenomena and it overlaps with other phases like pyrolysis and burning. For the purpose of model development, it is assumed as an exclusive phenomenon. Drying is predominant in the initial phase of flight at lower droplet temperatures while de-volatilization (pyrolysis) is negligible. Pyrolysis becomes significant at higher droplet temperatures. In the initial phase of droplet travel from point of injection to char bed, the particle loses mass in the form of water vapor. While moving down, the particle absorbs heat and expels water from it. In this phase, particle temperature is assumed as constant. The heat that is absorbed is utilized as latent heat of evaporation for water. In the following lines, the equations for calculating the heat $\&$ mass transfer in the black liquor droplets are described.

Water that is to be expelled in unit time is the ratio of available heat for vaporization of water $\left(Q_{\text {evap }}\right)$ and latent heat of vaporization $\left(h_{v}\right)$ of water. Drying can be described mathematically by (30).

$$
\frac{d\left(W_{\text {water }}\right)}{d t}=\frac{Q_{\text {evap }}}{h_{v}}
$$

where $W_{\text {water }}$ : Quantity of water, $\mathrm{kg}$

The heat dissipated in the form of latent heat of water vaporization by expelling the water vapor in incremental time period $(\Delta \mathrm{t})$ can be written as

$$
\Delta W_{\text {water }}=\frac{\Delta \cdot Q_{\text {evap }}}{h_{v}}
$$

The heat received by the droplet from the hot ambience in an incremental time period $(\Delta \mathrm{t})$ is

$$
\Delta Q_{\text {total }}=Q_{\text {total }}^{t+1}-Q_{\text {total }}^{t}
$$

The received heat is distributed to raise sensible heat and to supplement latent heat to expel the water as vapor. The rise in sensible heat is $\Delta Q_{\text {sen }}$ and the heat required to evaporate the water is $\Delta Q_{\text {evap. }}$. A heat balance gives

$$
\begin{aligned}
& \Delta Q_{\text {evap }}=\Delta Q_{\text {total }}-\Delta Q_{\text {sen }} \\
& \Delta Q_{\text {sen }}=Q_{\text {sen }}^{t+1}-Q_{\text {sen }}^{t} \\
& Q_{\text {sen }}=W_{p} C_{P}^{B L} T_{p C}
\end{aligned}
$$


The specific heat of the Black liquor $\left(C_{P}^{B L}\right)$ varies with concentration of the black liquor and a linear correlation [4] is used to determine the specific heat capacity as given in (29)(32).

$$
\begin{gathered}
C_{P}^{B L}=(1-S / 100) C_{P}^{W}+(S / 100) C_{P}^{S}+C_{P}^{E} \\
C_{P}^{S}=1684+4.47 . T_{p C} \\
C_{P}^{E}=\Gamma(1-S / 100)(S / 100)^{3.7} \\
\Gamma=4990-32.3 T_{p C}
\end{gathered}
$$

where

$C_{P}^{B L}:$ Heat Capacity of Black liquor, $\mathrm{J} / \mathrm{kg} .{ }^{\circ} \mathrm{C}$

$C_{P}^{W}:$ Heat Capacity of water, $4216 \mathrm{~J} / \mathrm{kg} .{ }^{\circ} \mathrm{C}$

$C_{P}^{S}$ Heat Capacity of dry Black liquor Solids, $\mathrm{J} / \mathrm{kg} .{ }^{\circ} \mathrm{C}$

$C_{P}^{E}$ Excess Heat Capacity, $\mathrm{J} / \mathrm{kg} .{ }^{\circ} \mathrm{C}$

$S$ : Black liquor solids concentration, $\%$

$T_{p C}$ : Temperature of the particle, ${ }^{\circ} \mathrm{C}$.

\section{E. Droplet Trajectory in Recovery Boiler during Drying}

Droplet travelled in the Recovery boiler in time $\mathrm{t}$ with velocity $u_{p}$ is

$$
T_{D}=u_{p}^{j} t
$$

where $T_{D}$ : Travel distance $(\mathrm{m})$

While moving down in the hot ambient atmosphere, the droplet receives heat, loses some of the water content, hence its weight resulting in decrease in droplet density which finally effects the velocity of the droplet. The velocity is calculated at time $\mathrm{t}+1$ by $(20)$ and the travel distance in incremental time $\Delta \mathrm{t}$ is calculated by the expression

At time $t+\Delta t$,

$$
\Delta T_{D}=u_{p}^{j+1} \Delta t
$$

$$
T_{D}^{j+1}=u_{p}^{j} t+u_{p}^{j+1} \Delta t
$$

\section{RESUlTS AND DISCUSSION}

The numerical calculations were carried out using MATLAB v7.0. The simulation studies were utilized to understand the effect of the following variables:

1) Effect of Particle diameter on drying time

2) Effect of initial particle velocity on desirable particle size for smooth operation.

Fig. 2 shows the drying time as a function of particle diameter for varying black liquor solids concentration. It is seen that the drying time increases with increase in particle diameter for completing the drying process. Predicted minimum size of the particle that reaches the char bed is around $0.9 \mathrm{~mm}$ and the maximum size that reaches char bed in dry condition is around $4.4 \mathrm{~mm}$. For given initial black liquor concentration, larger the droplet size, greater is the drying time. This basically would mean a higher proportion of the available flight space will be utilized for drying and hence the de-volatilization would be influenced significantly. An increase in initial concentration of black liquor will lead to reduction in drying time or alternately for the same drying time, larger droplets can be handled. This information will be extremely helpful in fixing the initial black liquor droplet size range for varying black liquor concentrations.

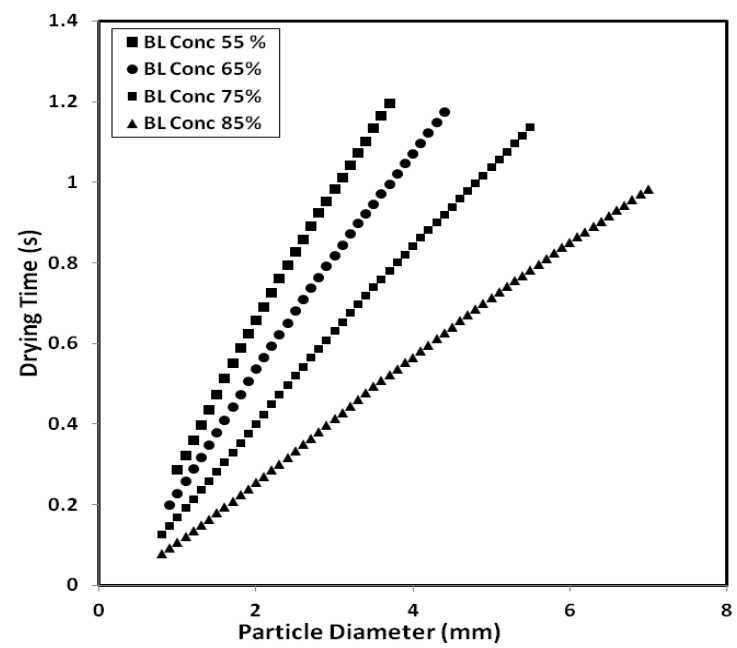

Fig. 2. Drying time vs particle diameter (Travel distance: $5.5 \mathrm{~m}$, initial particle velocity: $0 \mathrm{~m} / \mathrm{s}$ )

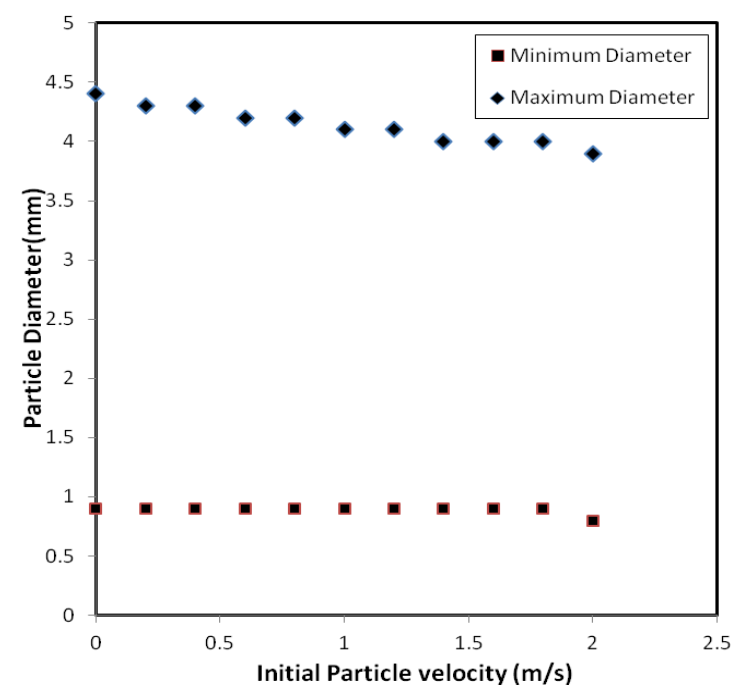

Fig. 3. Particle diameter vs initial velocity (Travel distance: $5.5 \mathrm{~m}$, initial solids concentration $65 \%$, initial particle velocity: $0 \mathrm{~m} / \mathrm{s}$ )

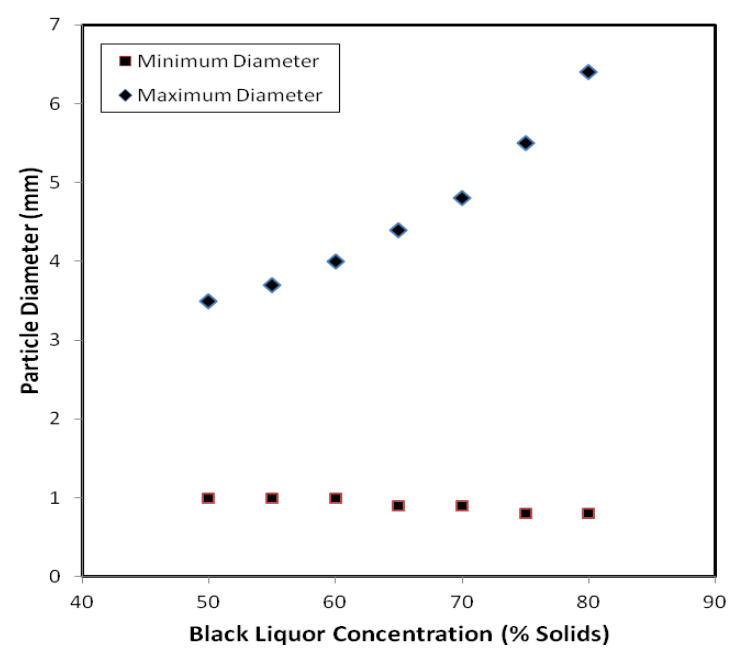

Fig. 4. Particle diameter vs black liquor solids concentration (Travel distance $=$ $5.5 \mathrm{~m}$, Initial particle velocity: $0 \mathrm{~m} / \mathrm{s}$ ) 


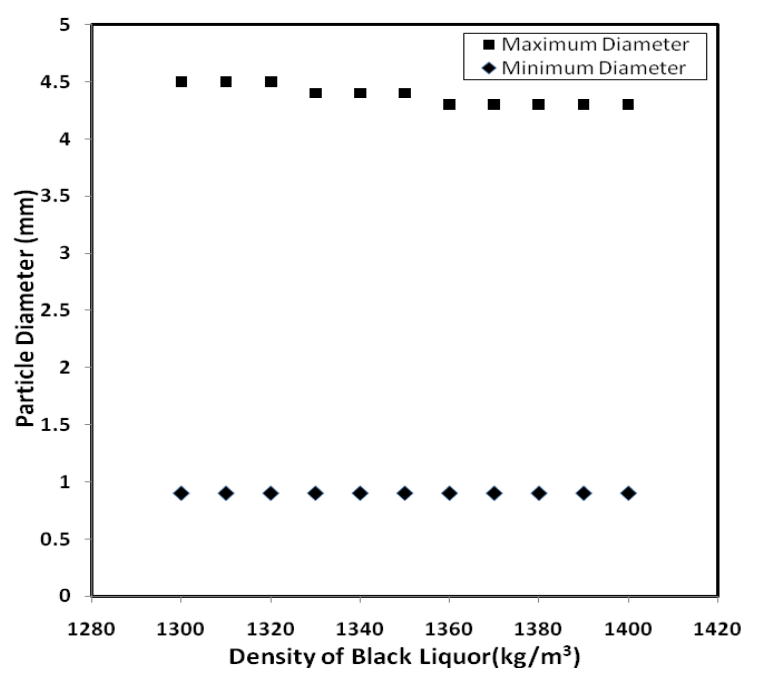

Fig. 5. Particle diameter vs black liquor density (Travel distance: $5.5 \mathrm{~m}$, initial particle velocity $=0 \mathrm{~m} / \mathrm{s}$, black liquor solids concentration $=65 \%$ )

Fig. 3 depicts the effect of initial particle velocity on desirable particle size at a solids concentration of $65 \%$. It is clear that there is an optimum particle size range for smooth operation. While larger particles beyond the range will reach the char bed in wet condition, particles smaller than the minimum will be entrained. Thus the selection of initial velocity will decide the range of operability with respect to droplet size.

In Fig. 4, the particle diameter as a function of Firing Black liquor solids concentration is shown. Increase in Black liquor solids concentration increases the maximum desirable size of the black liquor particle and decreasing the minimum desirable size. The graph shows that an increase in black liquor concentration will result in utilizing larger droplet sizes without difficulty. However this conclusion must be juxtaposed against the operating difficulties in pumping the black liquor into the firing guns.

Fig. 5 shows the particle diameter as a function of density of the black liquor. Increase in density of the black liquor decreases the maximum desirable size of the droplet that reaches the char bed. Black liquor density is dependent upon both the amount of inorganic chemicals present and the nature of cellulosic raw materials used. It is seen that the variation of black liquor density has minimal effect on the desirable particle sizes (maximum and minimum).

\section{CONCLUSIONS}

This paper presents the simulation results of the droplet dynamics inside the recovery boiler by predicting desirable particle sizes for different operating parameters during the drying phase of the droplet trajectory. The modeling and simulation studies strongly bring out the following conclusions for a given geometry of black liquor recovery furnace.

1) Initial droplet size has a great influence on the performance (Drying) of the furnace. Since drying time is the strong function of particle diameter, this has to be carefully controlled failing which a particle can be entrained if too small or a particle can be wet by the time it reaches the char bed. The safe operable zone for different initial particle velocities can be mapped.

2) The variation of black liquor concentration has relatively smaller impact on minimum droplet size (for entrainment) while variation in maximum diameter is significant.

3) The simulations can be dynamically used for operating boilers to fix right droplet sizes for varying black liquor concentrations for safe and economic operation.

Further work is necessary to capture the effect of devolatilization for predicting the flight time of droplets in the recovery boiler furnace. This can be done by integrating the mathematical model presented above with the kinetics for the devolatilization of the black liquor droplet [10].

\section{REFERENCES}

[1] M. Marklund. (October 2011). Black liquor recovery: how does it work? [Online]. Available: http://www.etcpitea.se/blg/document/PBLG_or_RB. pdf.

[2] M. P. Jarvinen, "Numerical modeling of the drying, devolatilization and char conversion processes of black liquor droplets," Ph.D. dissertation, Dept. Mech. Eng., Helsinki Univ. Tech., Finland, 2002.

[3] M. Jarvinen, R. Zevenhoven, E. Vakkilainen, and M. Forssen. "Black liquor devolatilization and swelling - a detailed droplet model and experimental validation," Biomass and Bioenergy, vol. 24, pp. 495-509, 2003.

[4] T. N. Adams and W. J. Frederick, Kraft Recovery Boiler: Physical and Chemical Processes, The American Paper Institute Inc., New York, 1988.

[5] R. Shennassa, "Dynamic carryover deposition in an entrained flow in an entrained flow reactor," Ph. D. dissertation, Dept. Chem. Eng. and Applied Chem., Univ. Toronto, Toronto, 2000.

[6] A. Macek, "Research on combustion of black liquor drops," Prog. in Energy and Combustion Science, vol. 25, pp. 275-304, June 1999.

[7] D. Q. Kern, Process Heat Transfer, McGraw Hill, New York, 1950.

[8] Y. Kim, J. G. Han, and Y. J. Kim. (October 2004). Numerical Analysis of Flow Characteristics of An Atmospheric Plasma Torch for finding the viscosity of the gas. [Online]. Available: http://arxiv.org/abs/physics/0410237

[9] T. M. Grace, W. J. Frederick, M. Salcudean, and R. A. Wessel, Black liquor combustion - Validated Recovery boiler modeling First Year Report, vol. 4, appendix IV, U.S. Department of Energy, Washington D.C., USA, August 1998.

[10] S. Ramesh, A. S. Chaurasia, H. Mahalingam, and N. J. Rao, "Kinetics of devolatilization of black liquor droplets in chemical recovery boilers Pyrolysis of dry black liquor solids," Int. J. Chem. Engg. and Applications, vol. 4, pp. 1-5, 2013.

S. Ramesh is a Ph. D. scholar in the Department of Chemical Engineering, Jaypee University of Engineering \& Technology, Guna, M. P., India. He obtained his B. Tech. in Chemical Engineering from Andhra University, Visakhapatnam in 1994 and has over 18 years' experience in chemical process industries.

H. Mahalingam is currently an associate professor and the head of Department of Chemical Engineering, Jaypee University of Engineering \& Technology, Guna, M.P., India. He secured his Ph. D. in Chemical Engineering from the National University of Singapore and was a post-doctoral researcher in France/Singapore. He obtained his B. Tech. and M. Tech. degrees in Chemical Engineering from Anna University, Chennai in 1994 \& 1996 and has about 14 years of teaching \& research experience.

N. J. Rao is currently the vice-chancellor, Jaypee University of Engineering \& Technology, Guna, M.P., India. He was formerly Director of the Central Pulp \& Paper research institute, Saharanpur as well as the Institute of Paper Technology, Indian Institute of Technology, Roorkee. He did his B. Tech. and M. Tech. in Chemical Engineering from the Indian Institute of Technology, Kharagpur in 1965 \&1967 and was awarded Ph.D. in chemical engineering by the University of Roorkee in 1975 . He has over 40 years of teaching, research $\&$ administrative experience. 